\title{
Reflexões sobre identidade judaica e gênero no seu processo de (re)territorialização no Rio Grande do Sul
}

\author{
Reflections on Jewish Identity and Gender in Its Process of \\ $(R e)$ Territorialization in Rio Grande do Sul
}

\author{
Maria Medianeira dos Santos \\ Universidade Federal do Rio Grande do Sul \\ medyageo@ig.com.br \\ Paulo Roberto Rodrigues Soares \\ Universidade Federal do Rio Grande do Sul \\ paulo.soares@ufrgs.br
}

\section{Resumo}

$\mathrm{O}$ artigo objetiva debater sobre identidade e gênero dentro da temática migratória. A análise da atuação do grupo cultural judaico no território gaúcho foi fundamental para a realização desta pesquisa científica. Um destaque especial foi destinado à mulher judia que é reconhecida como guardiã da memória judaica. Neste sentido, o estudo da sua atuação na Colônia Philippson (Itaara/RS) propiciou compreender a importância da figura feminina para o judaísmo. A construção da identidade social é sempre dinâmica, embora tenha uma aparente estabilidade. Ao reterritorializarem-se os imigrantes trazem consigo signos e representações, por outro lado acabam sendo influenciados pelos novos valores e hábitos que estão presentes na nova realidade espacial.

Palavras-chave: identidade; gênero; comunidade judaica, mulher judia.

\begin{abstract}
This paper aims to discuss identity and gender within the migration issue. The analysis regarding the Jewish cultural community performance in the gaucho territory was fundamental to achieve this scientific research. A special attention was given for the Jewish woman, who is recognized as the guardian of Jewish memory. In this sense, the study of their performance at Colônia Philippson (Itaara/RS) led us to understand the importance of the female figure in Judaism. The construction of social identity is always dynamic, although it shows an apparent stability. When immigrants reterritorialize, they bring with themselves signs and representations. On the other hand, they are influenced by new values and habits that are present in the new spatial reality.
\end{abstract}

Keywords: identity; gender; jewish community; jewish woman. 
Diante da diversidade cultural representada no Estado do Rio Grande do Sul, este artigo possui como pano de fundo a corrente migratória judaica. A preocupação central desta pesquisa científica foi buscar a construção e o entendimento sobre as questões identitárias e de gênero, durante o processo de (re) territorialização deste grupo cultural no Estado ${ }^{1}$.

A pesquisa foi norteada por alguns objetivos específicos, entre eles salientar como ocorrem as trocas culturais durante o processo de (desre)territorialização de um grupo cultural. Procuramos adentrar em algumas discussões teóricas, presentes no debate sobre a questão judaica nas ciências humanas e sociais: quem é judeu, como se constrói e se mantém a descendência e a identidade judaica. Finalmente, buscamos enfatizar o papel da mulher judia para manutenção da cultura judaica e sua atuação na Colônia Philippson, que estava localizada no município de Santa $\mathrm{Maria}^{2}$, no centro do Estado do Rio Grande do Sul.

É importante levantar como justificativa para o desenvolvimento deste artigo a necessidade de estudos em Geografia, tratando de correntes migratórias com foco para questões identitárias e de gênero. Neste sentido, delimitou-se como proposta para desenvolver este estudo o grupo cultural judaico. Pelo fato que, dentro desta abordagem geográfica verificamos um número ínfimo de pesquisas que possuem como escopo esta problemática desenvolvida.

Ao analisar o tema das migrações é comum os pesquisadores salientarem a existência de diversos motivos que movem as populações e ou grupos culturais a se deslocarem de seus territórios originais. Diante disto, pode-se afirmar que o aspecto econômico é destacado como o principal fator que propicia o movimento da (des-re) territorializações de pessoas ou grupos. Contudo, não é o único, principalmente quando se estuda a temática judaica, pois, as discriminações e as perseguições aos judeus foram fatores que contribuíram veementemente para a ocorrência das diásporas judaicas.

Ao longo da pesquisa utilizamos como procedimentos metodológicos a elaboração e aprofundamento do referencial teórico-metodológico e a pesquisa de campo no Instituto Cultural Judaico Marc Chagall (ICJMC), em Porto Alegre/RS, com a finalidade de levantar as fontes primárias e secundárias disponíveis no mesmo. Além da leitura e análise das entrevistas disponíveis no ICJMC foram realizadas outras, com membros representativos e significativos da comunidade judaica gaúcha, sendo que a fonte oral foi utilizada como um importante suporte metodológico.

\section{Sobre a matriz teórica: Gênero e Geografia}

No que se refere à configuração das espacialidades a pesquisadora Emili Schlögl enfatizou a necessidade de se buscar o entendimento de como os espaços são definidos e como são divididas as atribuições entre homens e mulheres. De modo que pontua o papel dos profissionais da Geografia, especialmente os vinculados à Geografia cultural, diante desta discussão.

Portanto, cabe às geógrafas e aos geógrafos, no contexto da geografia cultural, buscar, também na hermenêutica do gênero, o entendimento de como se definem espaços e se dividem atribuições entre homens e mulheres, verificando como esta divisão altera e configura as espacialidades. (SCHLÖGL, 2010, p. 274).

Para Joseli Silva (2009, p. 35) a concepção da construção social que transforma fêmeas e machos humanos em homens e mulheres considera "os gêneros masculino e feminino como papéis desempenhados socialmente". Nesta dualidade há incumbências específicas para ambos os gêneros no que se refere a sua função social a desempenhar na sociedade. Onde, nesta, é possível visualizar divergências no que se referem atuações com a família, no trabalho, na política e na esfera religiosa.

Na noção de patriarcado difundida nas primeiras versões dos estudos geográficos há o predomínio de relações hierarquizadas, quer dizer, a supremacia da autoridade masculina sobre a feminina. Silva (2009, p. 33), discorre como esta abordagem é compreendida pelas geógrafas feministas.

Como um sistema de relações hierarquizadas no qual os seres humanos detêm poderes desiguais, com a supremacia da autoridade masculina sobre a feminina em diversos aspectos da vida social, abrangendo desde os sistemas econômicos e sistemas jurídico-institucionais até os regimes cotidianos do exercício da sexualidade.

Não podemos esquecer que as imbricações para determinado gênero masculino $\mathrm{e}$ feminino estão permeados de atitudes e de valores, que diferem temporalmente e espacialmente. Diante disto, se pode perceber que as abordagens iniciais sob a ótica do

\section{Maria Medianeira dos Santose Paulo Roberto Rodrigues Soares}


patriarcado foram criticadas, pois eram generalistas por desconsiderar contextos históricos e espaciais. Silva (2009, p. 35) diz que esta foi enriquecida pela adoção do conceito de gênero, que possibilitou tanto avanços teóricos e como metodológicos:

[...] já que o espaço passou a ser um importante elemento para a compreensão das relações de gênero. Cada organização espacial é produto e condição das relações de gênero instituídas socialmente, contudo, hierarquizada, com primazia dos homens em relação às mulheres.

É importante esclarecer que para entendermos como foi realizado o processo de construção das espacialidades do universo feminino pelas judias no Estado do Rio Grande do Sul será necessário adentrar também no aspecto masculino. Pois, para compreender o universo representado pelas mulheres judias, tanto na esfera material como imaterial, tem-se que reconhecer o seu anteposto.

\section{O objeto de estud o: judeus/judias e questões identitárias}

Diante dessa discussão teórica este é momento ideal para adentrar na temática proposta. De modo que, é necessário buscar o alicerce humano que permeará este trabalho, ou seja, quem é judeu. Nesse ensejo, deve-se enfatizar que o judaísmo é regido como uma crença monoteísta, ou seja, baseado em um único Deus (Yhwh), porém dentro do judaísmo tradicional encontramos diferentes ramificações (ortodoxos, conservadores, liberais e reconstrucionistas).

Obviamente cada grupo desenvolveu suas discussões para a busca da resposta à questão 'quem é judeu?'. Essa definição de resposta se deu, em sua maioria, sob duas linhas gerais: pessoa que tenha passado por um processo de conversão ao judaísmo ou pessoa que seja descendente de um membro da comunidade judaica. Contudo, esses dois assuntos são repletos de divergências.

A socióloga Anita Brumer em pesquisa sobre os judeus do Rio Grande do Sul, realizou a construção do significado do conceito de identidade. Uma citação do escritor israelense Alef-Bet Iehoshúa, é o ponto de partida para a conceituação de judeu e da definição clássica da Halachá3. Segundo Brumer, (1994, p. 36): "[...] é judeu o filho de mãe judia ou aquele que se converteu ao judaísmo conforme a Halachá".

Dentro dessa visão, que tem apoio no judaísmo rabínico ortodoxo e conservador, percebe-se que a mulher dentro da religião é fundamental, já que é dela que se estabelece à descendência judaica. Essa tese têm força e raio de ação maiores por ser adotada pelo Estado de Israel, além de grande parte das comunidades ao redor do mundo. Onde reconhece como determinante apenas a descendência na linha materna e desconhece a linha paterna. Nesse sentido, Immanuel (1987, p. 18) nos diz que:

O status da mãe biológica (exclusivamente) determina o status da criança. Se a mãe biológica é judia, então não importa qual seja o seu pai biológico, todos os seus filhos são judeus. Se ela não for judia, é indiferente quem ou o que o pai é, todos os filhos também não são judeus.

No caso de um casamento misto (mãe judia e pai não judeu), os filhos nascem judeus. Se, por outro lado, somente o pai é judeu, "os filhos desse casamento não são judeus e, se quiserem tornar-se, terão de passar pela conversão religiosa, da mesma maneira que qualquer outro gentio" (ASHERI, 1987, p. 3). Para Unterman (1992, p. 140) a tradição judaica define judeu:

Como alguém que tenha nascido de mãe judia ou se convertido ao judaísmo, embora tenha havido movimentos dentro do judaísmo Reformista para também considerar judeu quem tenha nascido de pai judeu e mãe gentia.

Embora haja predominância dessa concepção não é possível generalizar, pois com a inserção de novas filosofias no seio do judaísmo há divergências quanto à descendência judaica. Cada grupo desenvolveu suas concepções diante da definição de como se conservaria a linha judaica, se matrilinearmente, patrilinearmente ou ambas as hipóteses.

A patrilinealidade é defendida pelo judaísmo caraíta e os judeus Kaifeng da China, grupos separados dos grandes centros judaicos e que desenvolveram sob tradições diferentes com base em costumes que remontam a vários séculos. Por último, existe a tese que ambos os pais podem dar ao filho a condição de judeu, a qual é defendida pelo judeus reformistas que reconheceram a validade da descendência paterna mesmo que a mãe não seja judia. Isto desde que a criança seja criada como judeu e se identifique com a fé judaica.

A questão da identidade é de primaz importância quando analisamos a dispersão judaica ocorrida durante os dois últimos milênios e fazemos a inevitável indagação: como os judeus mantiveram-se unidos no 
decorrer do tempo?

A identidade judaica para muitos judeus (e até para não judeus) é encarada tomando como base à hereditariedade. No entanto, existem outros significados que contribuem para que os judeus permaneçam sendo reconhecidos através do tempo com sua identidade. Para Gritti (1992, p. 11) a definição do judaísmo se dá principalmente: "Pelo reconhecimento que os outros fazem dos judeus. Caso o antissemitismo não fosse tão persistente, os judeus não se manteriam como grupo distinto".

Já Brumer (1994, p. 32-33) ressalta que há diversas correntes que serviram de base para a discussão da preservação da identidade cultural judaica:

a) religião e o modo como ela é praticada pelos judeus, bem como sua convivência conflituosa com os cristãos. A religião como fator de agregação acrescenta a importância de um território e de um idioma comum para a manutenção do judaísmo. b) Os materialistas: negam que a religião explique a sobrevivência dos judeus. Para eles, os judeus mantiveram-se através dos séculos graças as suas condições reais de existência, e principalmente ao papel econômico e social (sobretudo através do comércio e da usura) que desempenhavam nas sociedades em que se inseriam. c) Os efeitos do antissemitismo ajudaram para a manutenção da identidade judaica.

Outro aspecto da definição da identidade judaica diz respeito à possibilidade de visualizar os judeus como um grupo étnico. Neste sentido, Brumer (1994, p. 30) refere-se à identidade judaica tendo como base o conceito do grupo étnico: "Como uma coletividade humana baseada na crença de uma origem comum, real ou imaginária, que apresenta uma forma de organização social".

Apesar das várias diásporas ${ }^{4}$, de exílios forçados, de processos de marginalização e segregação, os judeus têm conseguido desenvolver mecanismos que os mantêm unidos uns aos outros, como se formassem fios que tecessem uma grande história grupal. Entre os mecanismos para a manutenção da identidade, Gritti (1992, p. 13) refere-se: “A memória histórica através das celebrações das datas mais importantes, e dos valores que são passados de gerações para gerações".

O geógrafo Pedro Geiger (1998, p. 89) comenta da relevância da memória durante o processo diaspórico. De modo que: "se existe uma herança, essa é de base cultural, fortalecida por especial valorização da memória e, que tem atrás de si milhares de anos vividos em diáspora".

Diante desta discussão é importante enfatizar o papel da mulher judia como 'guardiã da memória'. O seu reconhecimento é algo notório aos próprios relatos que a comunidade judaica vem preservando. Os mesmos expõem a incumbência da figura feminina como uma peça fundamental para a manutenção da cultura e das tradições da família judaica. A historiadora Lorena Gill (2001, p. 131) comenta que: "mais importante parece ser o fato de que cabe à mulher imprimir o caráter de coesão ao grupo do qual faz parte, através da importante função de guardiã da memória".

\section{A migração ju daica no Rio Grande do Sul}

Pedro Geiger (1998, p. 92) comenta que: "a mobilidade histórica judaica, embora, regra geral, forçada em grande parte, foi outro fator de discriminação, caracterizando o judeu como um corpo estranho".

Em uma entrevista realizada com a judia Berta Siminovich 5 ao responder a pergunta: 'O que levou a sua família a emigrar?' é possível verificar as perseguições que desencadearam a vinda para o Brasil, primeiramente de seu pai, posteriormente de sua família:

[...] a menor ajuda a alguém poderia ser interpretada como suspeita e espionagem e poderia custar a vida de um chefe de família. Assim um dia, meu pai, querendo ajudar um jovem a se encontrar com seus pais na Ucrânia, caiu em desgraça frente às autoridades fugiu, conseguindo chegar ao Brasil, que não exigia visto, e tinha nesta época, as portas abertas aos imigrantes. Cinco anos depois de chegar ao Brasil, ele recebeu sua família, esposa e filhos. (SIMINOVICH, 2004, p. 7).

No século XIX os judeus que estavam presentes em porções consideráveis do território russo, governado pelo regime czarista/tzarista. Havia diversas políticas direcionadas a alguns grupos éticos. Neste caso, percebeu-se o enquadramento dos judeus em leis e políticas que restringiam e delimitavam o seu espaço de atuação no interior das unidades territoriais. No decorrer do tempo, isto propiciou o desejo dos judeus de migrarem a outros territórios.

Frente a isto, o Estado do Rio Grande do Sul foi uma opção favorável para a (re) territorialização deste grupo cultural. Pois, ali este poderia alcançar a ascensão econômica, como também se pressupunha a

\section{Maria Medianeira dos Santose Paulo Roberto Rodrigues Soares}


ausência de preconceitos antissemitas. A 'Jewish Colonization Association' (ICA) ${ }^{6}$ foi a responsável pela idealização do projeto de colonização para os judeus neste Estado brasileiro. A mesma, financiou e organizou as colônias judaicas de Philippson (1904), em Santa Maria, e Quatro Irmãos (1909), em Erechim, cuja proposta estava assentada no direcionamento de um desenvolvimento territorial rural, na exploração agrícola por parte dos colonos judeus.

No entanto, a partir da segunda década do século $\mathrm{XX}$, os judeus migraram das colônias agrícolas de Philippson e de Quatro Irmãos para centros urbanos maiores, sendo Porto Alegre eleita como o núcleo urbano favorável para a formação de uma comunidade judaica. É importante ressaltar que esta aglutinação espacial teve a contribuição de imigrantes das colônias agrícolas fracassadas, bem como a vinda individual, migração espontânea, de judeus de outros países.

Em 2004, Ceres Maltz ${ }^{7}$ homenageou os judeus com uma mensagem dedicada aos cem anos da chegada organizada dos primeiros imigrantes judeus no Estado gaúcho. Maltz (2004, p. 15) nos diz o seguinte:

Em uma terra desconhecida, esses judeus começaram uma nova etapa de suas vidas, longe de um passado difícil. Poucos traziam objetos e bagagens, mas todos carregavam, no coração, a esperança de uma nova vida. O objetivo agora era a sobrevivência. Uma preocupação, contudo, sempre permanecia viva dentro deles: a preservação das tradições, dos costumes e da cultura judaica, as quais revelam um conjunto de valores e um estilo humano de existência.

Essa fala é esclarecedora na medida em que revela o estilo humano de existência judaica, através de suas principais preocupações, frente à nova realidade espacial. A judia relata que as apreensões eram referentes à preservação das tradições, dos costumes e da cultura judaica. Estas premissas foram essenciais, pois serviram como suporte para o desenvolvimento deste trabalho.

\section{As diáspo ras: resistência e plasticidade cultural}

Uma preocupação quando se estuda a dinâmica dos grupos humanos é como estes se deparam frente à nova realidade, pois é certo que haverá questões pessoais conflitivas. Diante disso, indaga-se: Como o elemento humano judaico lidou com todas estas mudanças no processo de re(territorialização) no Rio Grande do Sul. Isto pelo fato que o novo espaço possibilita tanto alterações que afetam o migrante na esfera material como imaterial.

Primeiramente, ao adentrarem no território desconhecido, os grupos sociais fazem um esforço para a construção de um ambiente material e simbólico semelhante ao que estavam inseridos anteriormente. O significado da permanência cultural é caracterizado como o enraizamento cultural ou falta de plasticidade. Nesta visão, La Blache (1913 apud CLAVAL, 1999, p. 90) comenta que:

A força do hábito torna-se tão forte que o grupo humano perde sua plasticidade. Ao invés de se adaptar ao meio, ele procura modificá-lo para permanecer com seus hábitos. Um exemplo é as migrações, aonde os recém-chegados em um país fazem de tudo para viver como estes o faziam no país de origem.

Embora, inicialmente estes grupos permaneçam fiéis a alguns laços culturais, também ocorre um processo de assimilação cultural. Convém ressaltar, que os traços culturais são processos dinâmicos, portanto, modificam-se no decorrer do tempo e no contexto histórico. Isto pode ser observado quando algumas verdades antes contestadas são esquecidas e retomadas por outras, ocasionando assimilações de alguns costumes e tradições. Assim, o aspecto cultural também passa por transformações de uma geração para outra. Claval (1999a, p. 135) comenta a respeito ao processo de aculturação:

A cultura muda mesmo quando a população que ela pertence acreditam que esteja congelada. Isto por que os homens são inventivos. Eles reagem a novos desafios que são impostos pelo meio físico ou pela vida social, melhorando suas técnicas. Enfrentando as dificuldades que nascem das transformações do ambiente social, modificando suas práticas, criticando os velhos valores e adotando novos.

O processo de trocas culturais entre grupos distintos ocorre através de uma dinâmica própria. Pois, dois grupos de culturas diferentes, entrando em contato, ficam em situação de um tomar elementos culturais do outro ou mais comumente, em situação de cada um receber elementos "difundidos" do outro. Assim, o contato e a difusão ocorrem com certa continuidade. Esse processo de transferência chama-se aculturação (KEESING, 1961). Este autor expõe o Modelo Básico de Aculturação $^{8}$, o qual permite 
visualizar como esse processo de trocas culturais ocorre entre grupos distintos (Esquema 1).

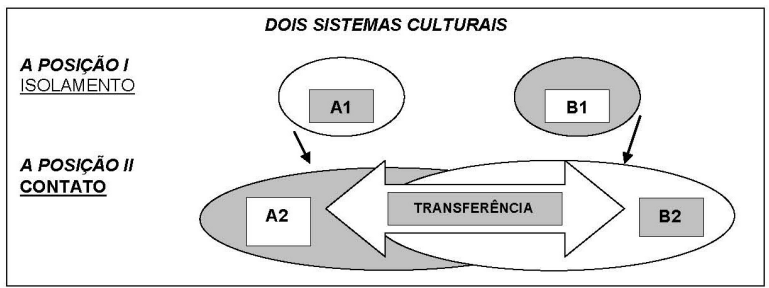

Esquema 1 - Modelo básico de aculturação. Fonte: Keesing (1961. Org.: Santos (2011).

No que se refere ao fenômeno da mobilidade dos judeus, pode-se afirmar que esses transladaram para uma nova paisagem, para uma nova realidade econômica, política e social. No Estado gaúcho encontraram outras tradições e costumes emergentes. No novo espaço, inicialmente, a manutenção cultural tornou-se a preocupação central dos imigrantes. Assim, os costumes e os traços representantes de sua cultura original logo foram materializados durante a sua apropriação do território gaúcho, como a construção de sinagogas, de escolas, de bibliotecas e de instituições filantrópicas. As práticas religiosas, a alimentação, a comunicação, com a manutenção do 'ídiche' e as comemorações religiosas aproximaram os imigrantes. Por outro lado, ocorriam mudanças com a introdução de novos alimentos à dieta, a substituição de roupas pesadas pelas típicas do gaúcho, que alguns imigrantes colonos adotaram, especialmente no interior, a convivência, na escola, das crianças com outras de fora da colônia e a colaboração de adultos não judeus nas lides agrícolas.

\section{O papel da mulher judia e suas atuações em Philippson}

Em 1904, o Município de Santa Maria recebeu as primeiras 38 famílias judaicas, reconhecidas oficialmente, no centro do Estado do Rio Grande do Sul. Esta comunidade judaica, na sua maioria, era originária da região da Bessarábia ${ }^{9}$. O destino para estes judeus foi o espaço rural, ou seja, a proposta da imigração estava assentada no desenvolvimento territorial rural.

Em uma família judaica, a esposa e a mãe são chamadas em hebraico Akeret Habayit, que significa literalmente o 'esteio da casa'. Neste sentido, percebese que a figura feminina é a responsável pela observância dos rituais judaicos repassados de geração em geração. Pinheiro (2000, p. 6) retrata que: "As primeiras memórias dos rituais estão invariavelmente associados à casa dos avôs e à figura da avó como centralizadora da união familiar através das festas". A imagem, a seguir, demonstra quatro gerações de pioneiras representadas pela mãe, filha, neta e bisnetos, em frente à casa da família na Colônia (Figura 1).

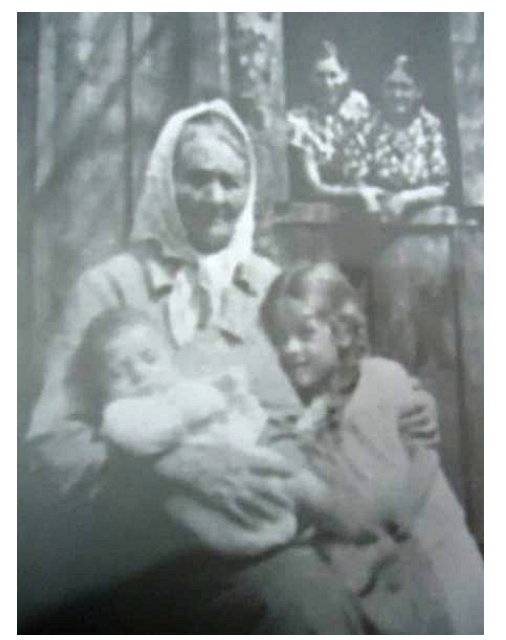

Figura 1 - Colônia Agrícola Barão Hirsh; 1950. Fonte: Histórias de vida (sa, p. 103)

O relato da judia Siminovich é enriquecedor, pois o mesmo possibilita reconhecer como foi realizado o repasse dos ensinamentos judaicos para seus irmãos. O fato é que ela era a filha mais velha e após um ano residindo no Brasil perdeu sua mãe. Isto acarretou na atribuição de responsabilidades que até então não eram de sua competência. O que pode ser visto através do seguinte questionamento direcionado a mesma: 'Como conseguiu preservar as tradições judaicas e a religiosidade que trouxe tão arraigada?'. Siminovich (2004, p. 9) respondeu da seguinte maneira:

Cedo tive que tomar conta de meus irmãos e procurei seguir todos os ensinamentos que minha mãe passou, seja nas tradições, seja na culinária para as festividades, dando assim continuidade e transmitindo o judaísmo para as outras gerações. Procurei transmitir a meus familiares o meu conhecimento, continuei a estudar por toda vida e acho que, quando se sabe o assunto, consegue-se transmiti-lo sem dificuldade.

Cosgrove, em texto clássico $^{10}$, desenvolve uma parte de sua narrativa, focando a cultura como algo que tem que ser constantemente reproduzida pelos seres humanos. Isto ocorre através de suas ações realizadas em tarefas rotineiras da vida cotidiana. $\mathrm{O}$ 
autor exemplifica a importância da prática humana afirmando que: "uma religião, por exemplo, ou um credo político só pode sobreviver se as pessoas os praticarem" (COSGROVE, 2004, p. 101-102).

A judia Pinheiro destaca quais eram as ações cultuadas pela sua mãe durante os rituais religiosos, além de desempenhar a tarefa de cozinhar pratos típicos para a família. Pinheiro (2000, p. 6) relata que:

É a mãe que coloca aquele véu na cabeça e reunia toda a família e era ela que preparava tudo e as rezas todas, não é! Com todas as comidas tradicionais! [...] comidas típicas sefaradis.

Os colonos de Philippson também comemoravam o Pessach onde havia a preparação do pão para essa cerimônia cultural. $\mathrm{O}$ trabalho para a constituição do mesmo era realizado em equipe e as tarefas eram divididas de acordo com o gênero. Também havia a divisão dos mantimentos que eram necessários para sua fabricação. A qual era fácil pelo fato da exigência de ingredientes básicos, bem como os mínimos recursos utilizados para a produção, sendo disponíveis em todas as dispensas dos colonos (SOIBELMANN, 1984).

O casamento era outra solenidade que os judeus realizavam em Philippson. Uma celebração bastante relacionada com outro código: a gastronomia. Neste sentido, as mulheres eram as responsáveis pela preparação dos alimentos nessa festa. Eizirik (1984, p. 32), comenta que as mulheres preparavam os seguintes pratos: "guefilte fish (peixe recheado), guebrutene iner (galinhas assadas), leikach (pão de ló) e shtrudel (doce folhado). As vizinhanças colaboravam e tudo era feito nas casas".

O Shabat (dia de descanso dos judeus) estende-se do anoitecer de sexta-feira à noite de sábado. Destacase o papel da mãe que tem a função de acender as velas na noite de sexta-feira, cuja finalidade é trazer mais luz para o lar. Henrique Ratnner (1977, p. 19) explica que isto acontecia:

[...] no lar, ao anoitecer da sexta-feira, a mãe acendia as velas, dando com isto inicio às celebrações do dia santificado. Esta é uma obrigação dedicada exclusivamente às mulheres judias.

A pesquisadora Gill (2001, p. 130) comenta que a única oração realizada pela mulher é a que acontece no momento em que se acendem as velas no shabat. Assim, a mesma, expõe todos os passos que a judia executa para efetuar sua função:

A mulher ou menina acende as velas e estende as mãos sobre elas num movimento circular em direção a si mesma por três vezes para indicar a aceitação da santidade do Shabat. Em seguida, cobre os olhos com as mãos, recita a benção abaixo e então descobre os olhos para fitar as luzes. Baruch atá a-do-nai e-lo-hênu mêlech haolam, asher kideshánu bemitsvotav, vetsivánu lehadlic ner shel shabat côdesh ${ }^{11}$.

Neste dia é celebrado um ritual em que são empregados utensílios como velas e outros. Os instrumentos também têm importância nos atos culturais. Isto fica bem demonstrado nas falas do escritor Moacir Scliar (1990, p. 24) que salienta os seguintes utensílios como: "A louça e os talheres para o Shabat e para os dias festivos, candelabros para as velas, o livro de orações: a milenar tradição era retomada, a ancestral corrente era refeita". A foto, a seguir, expõe um candelabro a Ménora utilizado pelas judias (Figura 2).

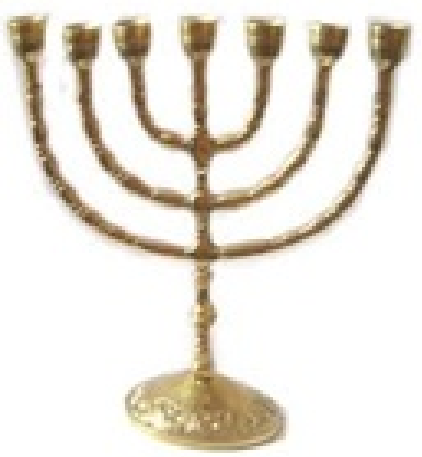

Figura 2 - Ménora. Fonte: Trabalho de campo. Porto Alegre, RS (2011).

Em uma entrevista realizada com Beatriz Faermann (1992, p. 27) foi feita a seguinte indagação: 'Como que vocês se preocuparam em repassar os valores do judaísmo para as meninas?'. A mesma deixou explícito o significado do shabat e como este dia era cultuado no seu seio familiar:

Nós fazíamos o "Shabat", sexta-feira aqui em casa, era "Shabat". Eu acendia as velas e nós fazíamos Shabat pras meninas. Sextas-feiras nós fazíamos questão de todo mundo jantar junto, não dava comida antes pra elas, elas sentavam na mesa, o pai, eu, 
né. Sentávamos, fazíamos "Shabat", nós cinco, né.

Na colônia Philippson houve ampla utilização da mão de obra familiar nas lides agropecuárias. A este respeito Soibelmann (1984, p. 42) comenta como era realizada a distribuição de tarefas entre homens e mulheres:

Todos trabalhavam. Lembro-me como as minhas irmãs capinavam a lavoura, partindo de casa pela manhã, voltando para o almoço e retornado em seguida para o trabalho. Enquanto isso meu pai e minha mãe iam para a mangueira tirar leite das vacas.

O cultivo do fumo proporcionou safras produtivas a ponto de um colono judeu chamado de Filschtiner implantar uma pequena indústria de cigarros. A fim de suprir a demanda de mão de obra, o autor Schweidson (1985, p. 164) comenta da utilização do trabalho feminino na indústria de cigarros:

A produção do fumo era toda, vendida a Chaim Jossel Filschtiner, que em 1908 ou 1909 montou uma pequena indústria de cigarros. Seu grupinho de graciosas operárias compunha-se das próprias filhas, sendo que uma delas, a Raquel, assombrava com a incrível rapidez no manuseio dos cigarros.

Por outro lado as atividades de mascateamento foram atuações atreladas à figura masculina. Contudo, antes mesmo da emigração total dos colonos de Philippson os seus filhos já desempenhavam atividades de mascateamento. Cita-se como exemplo o jovem judeu Schweidson que precocemente se tornou um mascate. Schweidson $(1985$, p. 221) conta que para se afastar parcialmente dos estudos: "falei do meu plano [...] com Margarida [...] a princípio achou graça. Não concebia o esdrúxulo propósito de me tornar mascate, com doze anos [...] acabaram concordando".

Isso foi reflexo dos escassos resultados obtidos com a agricultura. Os filhos homens buscaram atuar como mascates com o intuito de ajudar na subsistência da família. Diante dessa perspectiva, Soibelmann (1984, p. 49) discorre sobre o que os mascates judeus vendiam, bem como o meio de locomoção que utilizavam e a abrangência da área na qual atuavam:

Alguns se tornaram mascates, isto é compravam mercadorias variadas (fazendas, utensílios de casas, roupas e miudezas em geral) e saiam a cavalo. Com essa mercadoria percorriam as estâncias e colônias próximas a Philippson, vendendo e trazendo algum dinheiro para melhorar a situação aflitiva dos pais.

Entre os imigrantes da colônia existiram alguns que possuíam funções específicas tal como: o shoiched, o 'circuncisador', o childer, o felcher e o melamed. Estes profissionais foram essenciais para a manutenção da qualidade de vida, da saúde e da educação dos judeus. Deste modo, Alexandre (1967, p. 30-31) aborda algumas figuras que representaram à cultura judaica em Philippson:

Shteinbruck era o shoiched aquele que mata as galinhas e abate o gado do modo judaico e também foi incumbido da função de 'circuncisador'. Foi construído um grande matadouro e no centro um grande cepo onde o childer executaria o serviço, sendo que somente um único dia o açougue funcionava. Boris Wladimersky era o felcher, ou seja, uma espécie de médico e farmacêutico, em Filipson. Já Leão Back era o professor, quer dizer, o melamed de português que viera de uma universidade europeia para ensinar na escolinha rural.

Analisando outro contexto territorial (São Paulo), Henrique Rattner (1977, p. 28) salienta que a judia possuía atribuições que atingiam tanto o aspecto econômico como cultural. Da seguinte maneira: “[...] prover alimentação e proteção aos descendentes, e de manter a casa em geral". Podemos dizer que o papel da mulher na cultura judaica é fundamental. Esta possui algumas atribuições que the são peculiares, principalmente, no que se refere à manutenção e preservação da cultura judaica.

\section{Considerações}

Em 1904, o Estado do Rio Grande do Sul recebeu o primeiro projeto de imigração agrícola proposto ao grupo cultural judaico. Estes homens judeus e mulheres judias carregavam suas próprias histórias de vida, porém agora poderiam atuar com maior autonomia. Primeiramente, eles tiveram de organizar e construir suas casas e cultivar a terra visando o seu sustento. As atividades agropecuárias foram desempenhadas tanto pelos judeus como pelas judias.

Nesse espaço, era possível visualizar elementos identificadores da cultura judaica, nas quais foram construídos socialmente pelos seus membros. Depois

\section{Maria Medianeira dos Santose Paulo Roberto Rodrigues Soares}


de organizados eles direcionaram suas energias para a construção de elementos que consideravam como primordiais para o sustentáculo da sua cultura. Frente a isso, destaca-se a construção da sinagoga, escola e cemitério.

Havia atribuições distintas que eram incumbidas aos judeus e outras às judias. Entre as tarefas destinadas aos homens residia a realização de atividades culturais como a leitura da Torá; o abate de animais de modo judaico e realização da circuncisão eram feitos pelo shoiched; o melamed era encarregado de ensinar na colônia e por fim havia a atividade do felcher, que era designado a cuidar da saúde dos colonos.

Já as mulheres judias tinham a finalidade de manter a família coesa, principalmente, pelos preceitos do judaísmo. Cabendo ao universo feminino a realização de rituais específicos a mulher como o ato de acender velas e orar no Shabat. $\mathrm{O}$ aspecto gastronômico também é fundamentalmente atrelado ao desempenho feminino. O conhecimento dos pratos típicos é repassado de geração em geração, sendo algo muito valioso para as matriarcas da família. E a mulher judia, para a grande parte das ramificações do judaísmo, considera a mulher como a grande responsável pela manutenção do judaísmo através da hereditariedade, onde é desconsiderado o filho que nasce de pai judeu. Estes, consideram judeu quem nasce de mãe judia ou através de uma conversão judaica.

No decorrer do tempo, este grupo realizou outra reterritorialização no território gaúcho, desta vez visando o espaço urbano. Esta mobilidade populacional demonstra o aspecto da dinâmica que caracteriza os seres humanos. As diásporas judaicas são reconhecidas como movimentos populacionais étnicos, que ocorreram em diversas partes do mundo. A materialização cultural, deste movimento migratório, no Rio Grande do Sul, pode ser visualizada no município de Santa Maria e em Itaara, nos quais a presença dos judeus exerceu, em determinado tempo, influência na sua organização territorial.

1 É conveniente salientar que a dissertação intitulada: "A territorialidade judaica em Santa Maria/RS: uma contribuição à Geografia Cultural" contribuiu para a realização desta investigação científica. E, atualmente, este estudo faz parte de uma preocupação presente na Tese intitulada: Territorialidades Judaicas no Espaço Urbano de Porto Alegre/RS, que se encontra em desenvolvimento.

2 Porém, hoje, compreende as delimitações territoriais do município de Itaara. O Município de
Itaara desmembrou-se territorialmente de Santa Maria em 28 de dezembro de 1995 pela Lei n ${ }^{\circ} 10.643$. Atualmente, a localização da área compõe a Microrregião Geográfica de Santa Maria (018) e encontra-se inserida na Mesorregião Geográfica Centro Ocidental Rio-Grandense (03).

3 Segundo Unterman (1992, p. 112) este termo em hebraico significa: 'caminho' ou 'trilha'; tradição legalística do judaísmo, que se defronta geralmente com a teologia, a ética e o folclore da AGADÁ. Decisões haláchicas determinam a prática normativa, e onde há divergência, tais decisões, ao menos em teoria, seguem a opinião da maioria dos rabinos [... ].

4 Termo usado para referir-se às comunidades judias fora da terra de Israel. À diáspora começou ao fim do período do Segundo Templo, quando surgiram grandes centros judaicos em Babilônia, Alexandria, Roma e em todo o mundo grego-romano.

5 Foi uma das fundadoras da Entidade Sionista Feminina Na'amat Pioneiras de Porto Alegre/RS.

6 A Jewish Colonization Association, ou Yidishe Kolonizatsye Gezelshaft, em iídiche (ICA) é conhecida como a mais poderosa das instituições de amparo aos imigrantes judeus. Esta agência foi fundada por Maurice de Hirsch, em 1891.

7 Presidente da Entidade Sionista Feminina $\mathrm{Na}$ amat Pioneiras de Porto Alegre/RS.

${ }^{8}$ No Modelo Básico de Aculturação de Keesing os dois sistemas culturais previamente isolados (posição 1), entram em contato (posição 2). Cada um pode ser dado como um processo de aculturação, designação que se aplica também ao todo.

${ }^{9}$ Hoje conhecida como um pequeno país Moldova, localizada na porção oriental da Europa. Banhada pelo mar negro, estando inserida entre a Ucrânia e Romênia.

10 COSGROVE, Denis (2004). A Geografia está em toda parte: cultura e simbolismo nas paisagens humanas, original de 1989.

11 Tradução: Bendito és Tu, A-do-nai, nosso Deus, Rei do Universo, que nos santificou com seus Mandamentos e nos ordenou a acender a vela do santo Shabat. Retirado por Gill do Folheto publicado por Beit Chabat do Brasil, São Paulo, 2000.

\section{Referências}

ALEXANDR, Frida. Filipson: memória da primeira colônia judaica no Rio Grande do Sul. São Paulo: Fulgor, 1967.

ASHERI, Michael. O Judaísmo Vivo: as tradições e as leis dos judeus praticantes. Rio de Janeiro: Imago, 
BRUMER, Anita. Identidade em mudança: pesquisa sociológica sobre os judeus do Rio Grande do Sul. Porto Alegre: Federação Israelita do Rio Grande do Sul, 1994.

CLAVAL. Paul. Geografia cultural: o estado da arte. In: CORRÊA, Roberto Lobato; ROSENDAHL, Zeny (Orgs.). Manifestações da cultura no espaço. Rio de Janeiro: Ed. da UERJ, 1999. p. 59-97.

A Geografia Cultural. Florianópolis: Ed. da UFSC, 1999a.

COSGROVE, Denis. A Geografia está em toda parte: cultura e simbolismo nas paisagens humanas. In: CORREAA, Lobato. Roberto; ROSENDAHL, Zeny. (Orgs.). Paisagem, tempo e cultura. 2. ed. Rio de Janeiro: Ed. da UERJ, p. 92-123, 2004

EIZIRIK, Moysés. Aspectos da vida judaica no Rio Grande do Sul. Porto Alegre: Escola Superior de Teologia e Espiritualidade Franciscana. Caxias do Sul: EDUCS, 1984.

FAERMANN, Beatriz Starosca. Porto Alegre: ICJMCPOA, 1992. Entrevista $\mathbf{n}^{\circ} \mathbf{4 8 4}$. Concedida do Instituto Cultural Judaico Marc Chagall/Departamento de Memória. ICJMC- POA.

GILL, Lorena Almeida. Clienteltchiks: os judeus da prestação em Pelotas (RS): 1920-1945. Pelotas: Editora Universitária, 2001.

GEIGER, Pedro Pinchas. O povo judeu e o espaço. Revista Território, ano III, n. 5, jul./dez.1998.

GRITTI, Rosa Isabel. A imigração judaica para o Rio Grande do Sul: a Jewish Colonization Association e a colonization de Quatro Irmãos. 1992. Dissertação (Pós Graduação em História)- Pontifícia Universidade Católica do Rio Grande do Sul, Porto Alegre.

HAESBAERT, Rogério. Territórios Alternativos. Niterói: Ed. da UFF; São Paulo: Contexto, 2002.

Des-territorialização e identidade: a rede "gaúcha" no nordeste. Niterói: EDFF, 1997.

IMMANUEL, Jacob. Quem é judeu?. Canadá: Shofas association of América, 1987.
KEESING, Felix. Antropologia Cultural: a ciência dos costumes. Rio de Janeiro: Fundo de Cultura, 1961.

MALTZ, Ceres. Mensagem da Presidente da Na'amat Pioneiras Porto Alegre. Na'amat Pioneiras Brasil, n 45, Bazar, 2004. p. 15-16.

PINHEIRO, Geni. Porto Alegre: ICJMC-POA, 2000. Entrevista $\mathbf{n}^{\circ} \mathbf{0 3 5}$. Concedida do Instituto Cultural Judaico Marc Chagall/Departamento de Memória. ICJMC- POA.

RATTNER, Henrique. Tradição e Mudança: a comunidade judaica em São Paulo. São Paulo: Ática, 1977.

SANTOS, Maria Medianeira dos. A territorialidade judaica em Santa Maria/RS: uma contribuição à Geografia Cultural. 2009. Dissertação (Pós Graduação em Geografia e Geociências)- Universidade Federal de Santa Maria, Santa Maria, 2009.

SCHLÖGL, Emerli. A Geografia Cultural e as representações simbólicas do sagrado feminino. Revista Latino-americana de Geografia e Gênero, Ponta Grossa, v. 1, n. 2, p. 270-279, ago. / dez. 2010.

SCHWEIDSON, Jaques. Judeus de bombacha e chimarrão. Rio de Janeiro: José Olympio, 1985.

SCLIAR, Moacyr. Caminhos da esperança: a presença judaica no Rio Grande do Sul. v.2 Porto Alegre: Riocell, 1990.

SILVA, Joseli Maria (Org.) Geografias subversivas: discursos sobre espaço, gênero e sexualidades. Ponta Grossa. Paraná, Brasil. Editora Todapalavra, 2009.

SIMINOVICH, Berta. Entrevista com Berta Siminovich: uma das fundadoras da $\mathrm{Na}$ 'amat Pioneiras. Na'amat Pioneiras Brasil, n 45, Bazar, 2004. p. 7-9.

SOIBELMANN, Guilherme. Memórias de Philippson. São Paulo: Canopus, 1984.

UNTERMAN, Alan. Dicionário Judaico de lendas e tradições. Rio de Janeiro: Zahar, 1992.

Recebido em: 1 de dezembro de 2011. Aceito em: 20 de fevereiro de 2012. 